Article

\title{
Experimental Investigation on the Deformability, Ultrasonic Wave Propagation, and Acoustic Emission of Rock Salt Under Triaxial Compression
}

\author{
Haoran Li ${ }^{1,2, *}$, Zhikai Dong ${ }^{1}$, Zuolin Ouyang ${ }^{1}$, Bo Liu ${ }^{1}$, Wei Yuan ${ }^{1, *}$ and Hongwu Yin ${ }^{3}$ \\ 1 Structural Health Monitoring and Control Institute, Shijiazhuang Tiedao University, Shijiazhuang 050043, \\ Hebei, China; dzk0439@163.com (Z.D.); oyz197@126.com (Z.O.); liub33851809@163.com (B.L.) \\ 2 Department of Energy and Mineral Engineering, G3 Center and EMS Energy Institute, Pennsylvania State \\ University, University Park, PA 16802, USA \\ 3 State Key Laboratory of Geomechanics and Geotechnical Engineering, Institute of Rock and Soil Mechanics, \\ Chinese Academy of Sciences, Wuhan 430071, Hubei, China; hong5yin@163.com \\ * Correspondence: lihaoran@stdu.edu.cn (H.L.); yuanwei@stdu.edu.cn (W.Y.); \\ Tel.: +86-311-8793-5307 (H.L. \& W.Y.)
}

Received: 17 December 2018; Accepted: 5 February 2019; Published: 14 February 2019

\begin{abstract}
Ultrasonic waves, which constitute an active testing method, and acoustic emissions (AE), which can be applied as passive testing technology, can reveal rock damage processes in different ways. However, few studies so far have simultaneously adopted both, owing to the limitations of the experimental apparatus. However, the simultaneous use of both methods can improve the experimental efficiency and help to understand the rock damage evolution more comprehensively. In this study, concurrent experiments of ultrasonic waves and AE activities were carried out on rock salt under uniaxial compression, and the deformation characteristics were measured. The fracture process was divided into four stages with individual characteristics: the elastic compression stage, brittle-ductile transition with crack initiation, brittle-ductile transition with damage initiation, and plastic deformation and strain hardening stage. The ultrasonic wave velocity, crack density, ultrasonic wave amplitude, and attenuation coefficient were obtained to evaluate the damage process. The ultrasonic wave amplitude and the attenuation coefficient were recommended as forecast indicators, owing to their sensitivity and operability of measurement. The confining pressure had an inhibitory effect on crack expansion and on the AE activity, and the damage ultimate stress was defined and determined according to the AE activity and energy release characteristics. Four critical strengths of the crack initiation threshold stress, dilatancy boundary stress, short-term strength, and damage ultimate stress of rock salt were determined and then discussed. These results are valuable in evaluating rock damage and guiding the operation of underground salt caverns.
\end{abstract}

Keywords: salt cavern; damage ultimate stress; energy release; ultrasonic wave; acoustic emission

\section{Introduction}

Salt formations are almost perfectly impermeable and they have good creep properties; therefore, many countries have used them to store energy and nuclear waste [1-4]. Underground salt caverns are the safest way to protect energy storage containers from fire and explosion. However, several accidents have occurred, resulting in substantial damage to property and causing environmental disaster in the past forty years [5-8]. According to statistical analyses, 38\% of accidents were caused by salt over-creep or cavern structural instability. Therefore, research on the damage evolution laws of rock salt can provide scientific guidance for the design, construction, and operation of rock salt gas storage. Up to now, many methods have been applied to study rock damage, such as scanning electron microscopy, 
computed tomography $(\mathrm{CT})$, and density or infrared radiation detection. However, they are not widely used, owing to the strict requirements on testing conditions or equipment. In recent years, an active method, as represented by ultrasonic wave detection, and a passive method, as represented by acoustic emission (AE) monitoring, have been accepted by many scholars, and they have become essential tools in analyzing and predicting rock damage.

Ultrasonic waves are a good index for evaluating the change of internal structure and mechanical properties of rocks. When the elastic wave encounters certain obstacles during propagation, such as inclusions, holes, and cracks, ultrasonic attenuation will occur. This process is presented by the decline of ultrasonic wave velocity or amplitude [9]. In the 1970s, Oconnell and Budiansky [10,11] studied the differences of the elastic modulus in crack-bearing rocks and crack-free rocks, and obtained a relationship between ultrasonic wave velocity and the elastic modulus of rock mass. An equation depicting ultrasonic wave velocity and fracture density was established. However, it was not widely used, owing to the difficulty of P-wave (Primary wave) and S-wave (Shear wave) velocity measurement at that time. In the 1990s, Bellang et al. [12] evaluated the damage process of limestone during the freeze and thaw cycles using ultrasonic methods and Falls and Young [13] determined the excavation-disturbed zone of a granite tunnel using AE and ultrasonic techniques. In the 21st century, research on rock damage using ultrasonic methods became popular. Researchers [14-16] applied ultrasonic wave attenuation to detect and study damage development in granite and then demonstrated that the ultrasonic wave velocity was a good indicator for the physical and mechanical capability of rocks, as well as the gestation environment. Wang and Li [17] and Li et al. [18] showed the developing velocities of S-waves and P-waves through shale during uniaxial and triaxial loading, separately. Schulze et al. [3] determined the dilatancy boundary of rock salt through the change in ultrasonic wave velocity and permeability. Chen et al. $[19,20]$ carried out multiple sets of experiments on rock salt to obtain the relationship between the ultrasonic wave velocity variations and the process of salt crystal self-healing.

The AE activity is highly contrasted with the damage evolution of rock materials, which has become an important indicator in predicting rock rupture. Mogi [21] was the first to study the differences in $\mathrm{AE}$ sequences between rock samples and synthetic samples and revealed the $\mathrm{AE}$ pattern of rocks during the damage process. Rao and Ramana [22], Filimonov et al. [23], and Rodríguez et al. [24] investigated the AE activities of marble, salt rock, and granite under cyclic loading, respectively; and, the memory effect of AE of rock had been confirmed. Chen et al. [25] and Ge and Sun [26] analyzed rock damage during different freezing-thawing cycles using AE activity. Ren et al. $[27,28]$ studied the effect of uniaxial loading rate on the AE frequency of rock salt and the number of AE events. Alkan et al. [29] determined the dilatancy boundary by the AE characteristics during different strain stages in the triaxial compression test of rock salt.

The presented research has broadened the application of ultrasonic wave and AE technology, which promoted the development of quantitative evaluation of rock damage. However, some of the limitations of these methods are the following: (1) although ultrasonic wave and AE techniques are important means in studying the physical and mechanical properties of rocks, both methods were used simultaneously in the same loading test in only a few experiments; (2) due to the limitation of the test equipment, the $\mathrm{AE}$ activities and the locations of rock under the triaxial loading condition are studied less. Although some researchers $[23,30]$ have tried to position the AE receiving sensor outside the triaxial chamber, this change in the method caused a large test error.

In order to address these challenges and to answer open questions in the field, in this paper, an integrated testing device was used to study the ultrasonic wave and AE activity of rock salt under triaxial compression conditions (Section 2). The features of rock deformation, ultrasonic wave attenuation, and AE events and locations were recorded and then analyzed (Sections 3 and 4). The obtained results provide a new insight into the damage evaluation in salt rock and they lay an important foundation for further studies. 


\section{Experimental Program}

\subsection{Experimental Apparatus}

A TAW-2000 rock mechanics testing machine (Chaoyang Testing Instrument Corporation of Changchun) carried out the triaxial loading stress, which can provide a maximum axial stress of $4600 \mathrm{kN}$ and a maximum confining pressure of $200 \mathrm{MPa}$. Both axial and lateral strain gauges were applied to record the rock deformation during the loading process, and vertical and lateral displacements were used as feedback signals to control the loading stress. The other selected apparatus was an integrated device with ultrasonic wave and AE activity, RT-100 (Zhongyi Geotechnical Instrument Corporation of China), which was composed of an ultrasonic wave testing system, an AE testing system, and a data recording system. Two sealed indenters were included in the ultrasonic wave testing system, UWS-A and UWS-B, and two S-wave sensors (Model: SWC37-0.5-SHEAR, as produced by the Physical Acoustics Company, Princeton Junction, NJ, USA), and one P-wave sensor (Model: NANO-30, produced by the Physical Acoustics Company, Princeton Junction, NJ, USA) were sealed in each of them. SWC37-0.5-SHEAR has a central frequency of $350 \mathrm{kHz}$, and NANO-30 has a central frequency of $300 \mathrm{kHz}$. The sensors selected meet the following requirements that are suggested by ISRM: $\mathrm{D} \geq 10 \lambda, \lambda>\mathrm{d}, \mathrm{L} \geq 10 \mathrm{~d}, \mathrm{D}$ is the minimum transverse size of the specimen, $\lambda$ is the wavelength, $\mathrm{d}$ is the average size of particles in the specimen, and $\mathrm{L}$ is the length of the specimen. Therefore, the specimen can be regarded as an infinite medium in this study. During the testing process, two indenters were placed on the two ends of the sample. UWS-A was activated to transmit a high voltage electrical pulse signal, which could be received by UWS-B when it reached the other end of the sample. The excited signal is a square wave with a frequency of $300 \mathrm{kHz}$ and a high voltage of $150 \mathrm{~V}$, and the signal period is $30 \mathrm{~s}$ are used this study. The design principle and testing method of RT-100 have been published [31] and are used to synchronously monitor ultrasonic wave and AE activity for rock samples. This apparatus was developed by the authors and it has been patented in China (ZL2014101711015). A diagram of this device is shown in Figure 1a.

\subsection{Test Specimens}

The salt specimens were sourced from Jintan Salt Mine, Jiangsu Province, China. The rocks were extracted from approximately $850-878 \mathrm{~m}$ below ground level. In order to eliminate the influence of impurities on the mechanical and acoustic characteristics of rock salt, the $\mathrm{NaCl}$ mass fraction of the sample was selected to be above $90 \%$. The original rocks were polished into standard cylinders with a diameter of $100 \mathrm{~mm}$ and a length of $200 \mathrm{~mm}$, and the smoothness of the samples was controlled to within $0.02 \mathrm{~mm}$. Four standard rock samples were processed in this study and they were tested under different confining stress pressures. In statistical theory, the larger the sample size, the more reliable the data will be. However, analysis of statistical results was not the focus of this paper.

\subsection{Test Procedures}

In this study, the deformation characteristics of rock salt under triaxial compression conditions were tested when the confining stresses was 5, 10, 15, and $20 \mathrm{MPa}$. The axial loading force was controlled by a lateral strain increments rate of $0.6 \mathrm{~mm} / \mathrm{min}$. The amplifiers for ultrasonic waves and AE signals were set to $40 \mathrm{~dB}$. The noise threshold was set to $40 \mathrm{~dB}$ as well. The sampling rate of ultrasonic waves and AE signals is $2 \mathrm{MHz}$. The ultrasonic wave velocities were measured every $30 \mathrm{~s}$, while AE information was monitored during all the testing times.

The installation of the sample and sensors followed the steps that are described in the following. First, a coupling medium (Model: PXUAC, produced by Pengxiang Technology Company, Changsha, Hunan province, China) was smeared evenly on the surface of a salt sample to ensure full contact between the sample and the surrounding medium. Second, UWS-A and UWS-B (as shown in Figure 1b) were placed at both ends of the sample. In order to keep the sample away from a high-pressure liquid in the chamber, UWS-A, UWS-B, and the salt sample were sealed together by rubber thermoplastic 
casing. Subsequently, the rock sample was set on the base of the rock mechanics testing machine, and axial strain gauges, lateral strain gauge, and AE sensors were fixed around the sample. Each sensor is designed with grooves for holding the spring. The arrangement of AE sensors presents a characteristic of spatial symmetrical distribution, and the distance between them should be as far as possible to ensure a wider range of monitoring. Meanwhile, the operability of sensor installation should also be considered. The arrangement of the different sensors is shown in Figure $1 \mathrm{~b}$ and the layouts of six AE sensors are shown in Figure 1c.

(a)

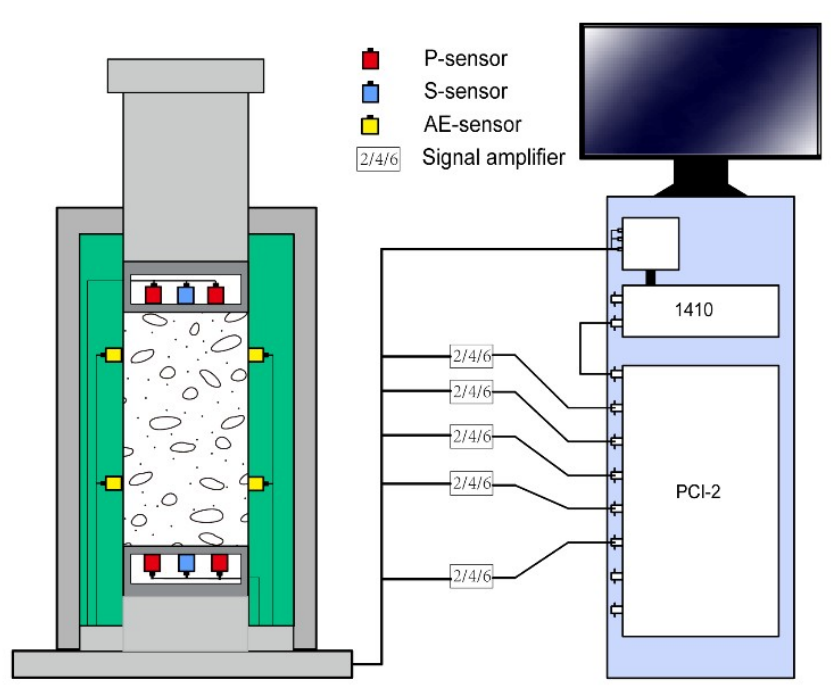

(b)

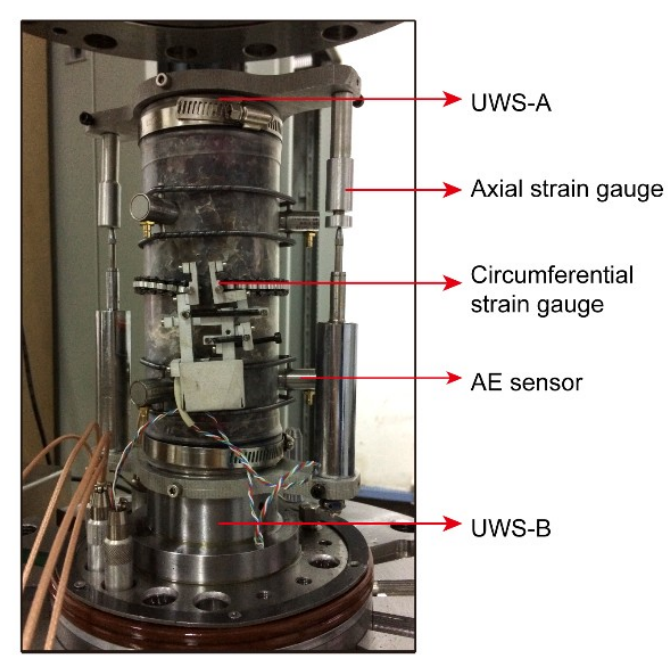

(c)

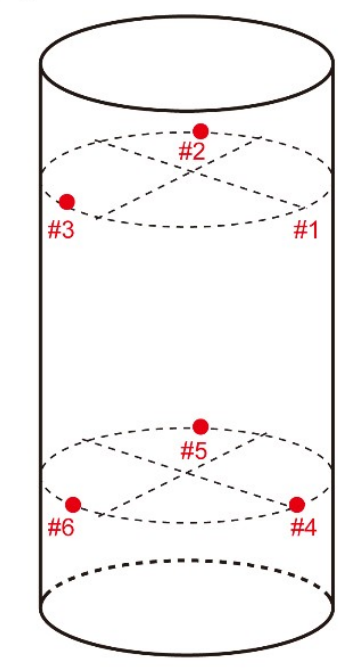

Figure 1. Triaxial compression loading test of rock salt specimens: (a) diagram of an integrated testing device with ultrasonic wave and acoustic emission (AE) activity; (b) installation of strain gauges, ultrasonic sensors, and AE sensors; and, (c) layout of six AE sensors.

\section{Experimental Results}

\subsection{Deformation Characteristics}

Salt rock is a kind of "soft" rock, which does not show "yield" characteristics under triaxial stress conditions. The higher the confining pressure level, the more obvious this feature becomes [32]. A typical axial stress-strain relationship of a "hard" rock under a triaxial compression test is presented in Figure 2a [33]. The stages of crack closure, elastic behavior, stabilized-growth of cracks, and 
accelerated-growth of cracks can be clearly distinguished. However, these clear boundaries between the different stages are not present for rock salt, as shown in Figure 2b. Not only is the crack closure stage unclear, but also the peak stress cannot be easily detected. Even though its axial strain had exceeded 5\%, rock salt still had a higher load carrying capacity. Based on the axial stress-strain curve and volume strain information, the deformation process of rock salt can be divided into four stages (Figure $2 b$ ): the elastic compression stage, the brittle-ductile transition with crack initiation, the brittle-ductile transition with damage initiation, and the plastic deformation and strain hardening stage $[29,34]$. The details of these stages are, as follows.

(a)

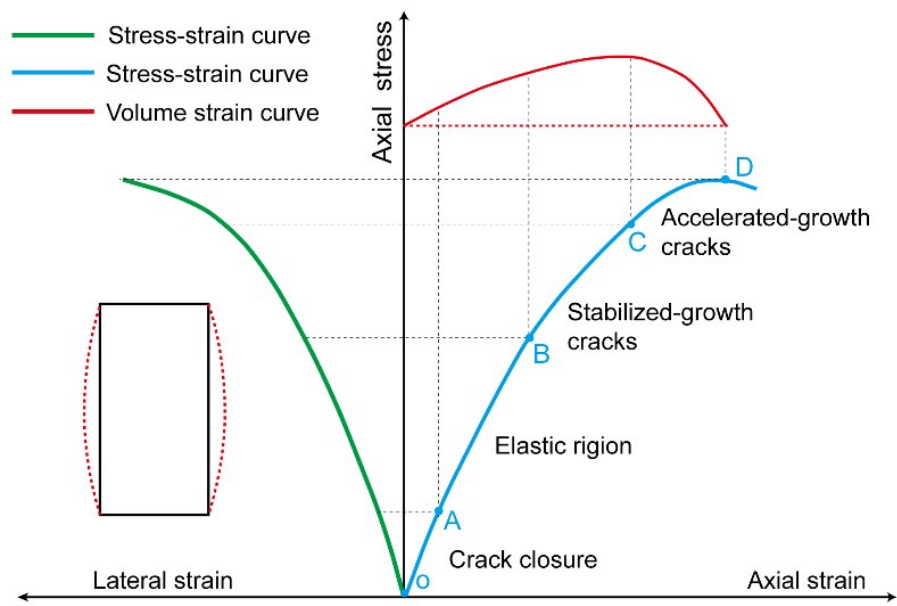

(b)

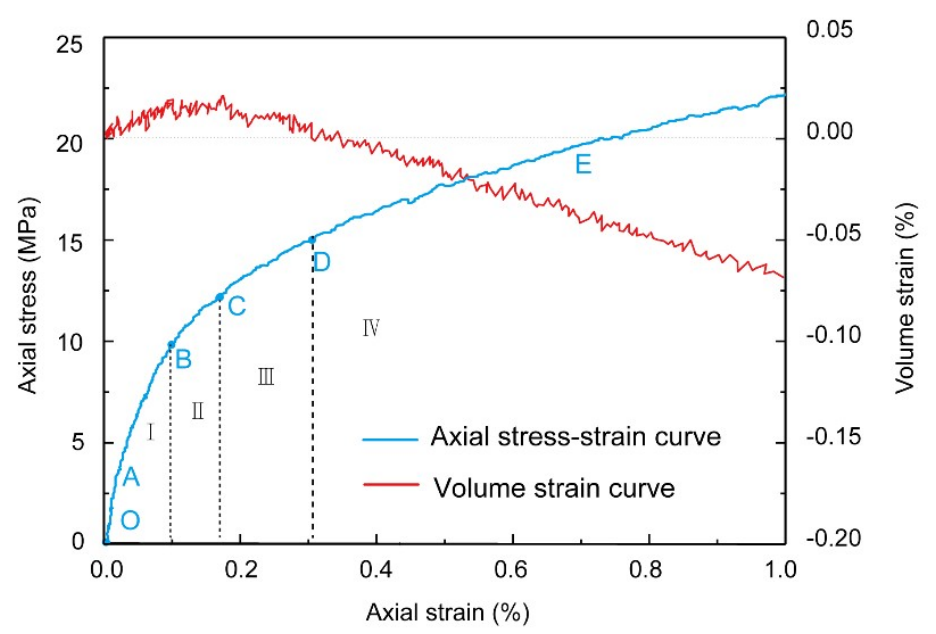

Figure 2. Deformation characteristics of rock under a triaxial loading test: (a) stress-strain curve for typical hard rock; and, (b) four deformation stages of rock salt under the confining pressure of $5 \mathrm{MPa}$.

Stage I, the elastic compression stage (OB). When the rock was drilled from the deep underground, its original structures were disturbed due to the reduction of the surrounding stress [35]. In this stage, the salt crystal became more compact under compressive stress from three directions, which could be regarded as compensation for artificial structural disturbance that is caused by excavation. The elastic compression stage was a short-term and completely reversible process. The first part of this stage was primary crack closure. Subsequently, axial stress-strain curves and volumetric deformation were dominated by a linear change responding to the increasing of loading stress. The modulus of elasticity can be obtained by this linear slope of the axial stress-strain curve. This stage ended at the elastic linearity boundary, which is also called the crack initiation threshold (point B in Figure 2b). 
Stage II: brittle-ductile transition with crack initiation (BC). The salt samples experienced a transition from elastic deformation to plastic deformation in this region and the elastic deformation played a leading role. A few micro-cracks were generated with a controllable development, and the slippage among the salt crystals began to occur. The compressive volume strain of rock salt first significantly increased and then reached its peak at the end of this phase. This region began at point $B$, which was recorded as the crack initiation threshold, and it ended at point $C$, which was defined as the dilatancy boundary. During this process, AE activity began, while S-waves' and P-waves' velocities remained steady.

Stage III: brittle-ductile transition with damage initiation. When the loading stress exceeded the dilatancy boundary, the lateral strain became much larger than the axial strain, which brought about a dilatancy to rock salt. In previous studies [29], rock permeability would sharply increase when dilatancy occurred, which posed a threat to the sealing ability for the gas storage. During this stage, the volumetric strain curve turned from the peak to 0 , and the axial stress at the volume strain of 0 (point D in Figure 2b) was regarded as the short-term strength of the rock salt. This was a transitional phase from elastic deformation to plastic deformation, and the latter had a dominant position. An unstable rapidly developing crack growth occurred, which was accompanied by intense AE activities.

Stage IV: the plastic deformation with hardening strain. After the loading axial stress exceeded the short-term strength, the volumetric strain of the salt sample continued to increase and it exhibited viscoplastic deformation. Although the rock salt had undergone large axial deformation, it did not "yield" with the ability to carry stress, which was exactly the difference between rock salt and other rocks. The salt sample exhibited a typical drum-shaped failure characteristic under three-dimensional stress conditions, as shown in Figure 3.

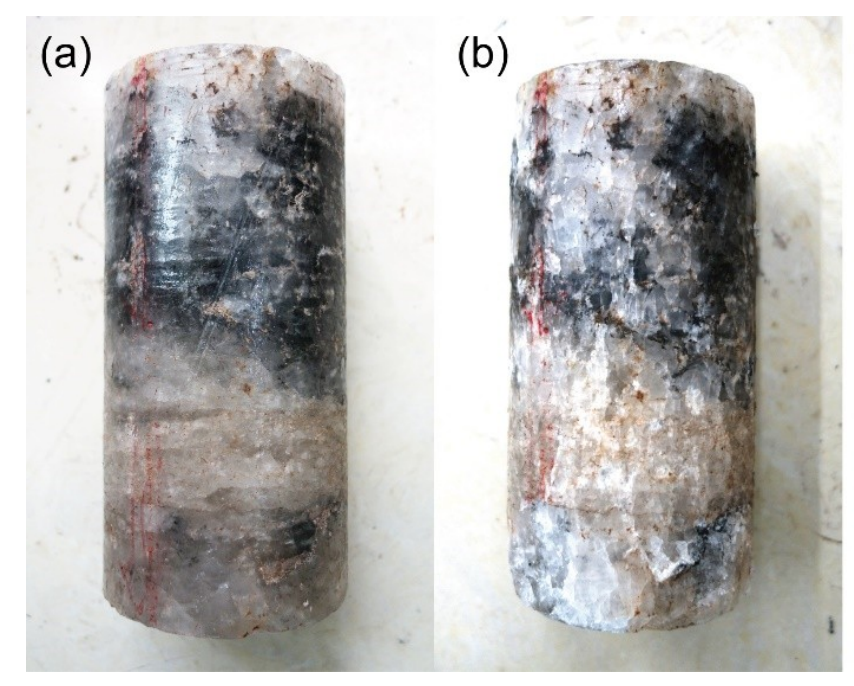

(c)

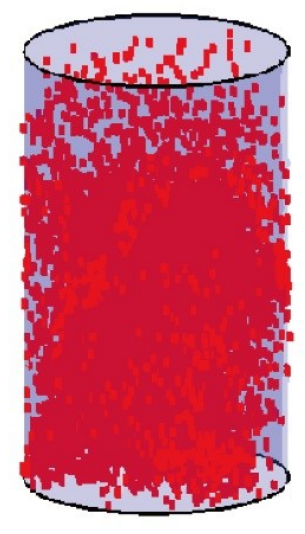

Figure 3. Comparison of rock salt failure characteristics: (a) picture of rock salt before test; (b) picture of rock salt after triaxial loading test; and, (c) AE locations of rock salt under triaxial loading test.

\subsection{Ultrasonic Wave Analysis}

When elastic waves encounter obstacles during propagation, such as inclusions, holes, and cracks, the wave velocity decreases, which can be calculated by the length of the sample and the propagation time [9]. The propagation time is obtained by interpreting the received waveform information. Figure 4 shows a set of the excited and thereceived ultrasonic waveform. 
(a)

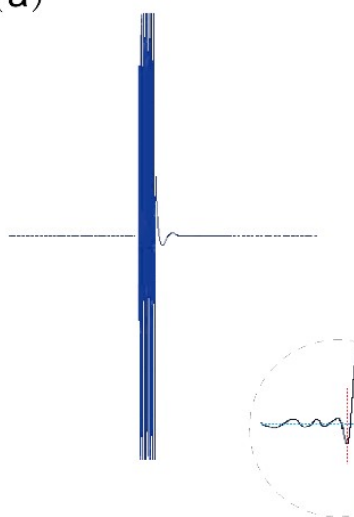

(b)

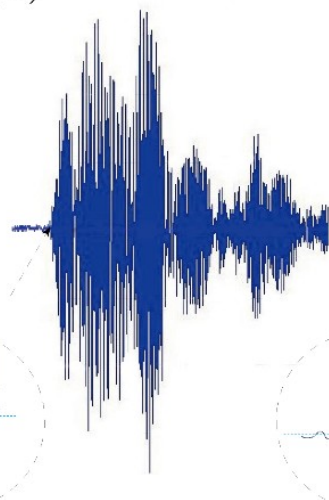

(c)

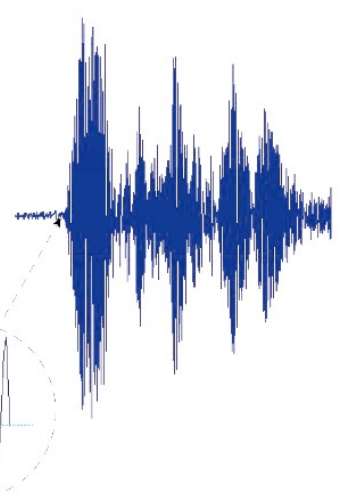

(d)

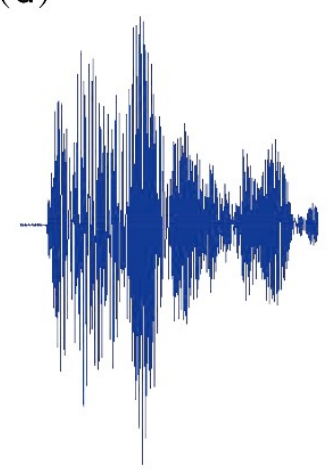

Figure 4. Characteristics of different types of waveform: (a) a excited ultrasonic waveform; (b) a received P-wave waveform; and, (c) a received S-wave waveform; (d) a received AE waveform; the blue dotted line is the symmetrical centerline of the waveform; the red dotted line is the recorded time of arrival of ultrasonic signal.

The change of ultrasonic wave velocities through rock salt under triaxial loading stress is shown in Figure 5a. Both P-waves and S-waves had slightly increased wave velocities at the elastic compression stage. Subsequently, their velocities remained stable during the brittle-ductile transition process. This finding was unexpected and different from typical brittle rock [18], and it suggested that the new cracks that were generated inside the rock were negligible during this period. One possible reason is that the sliding and embedding actions among the salt crystals are controlling rock deformation, even if the axial strain has reached $0.5 \%$. When the crystal slide exceeded their limits at the plastic deformation stage, a large number of micro-cracks were produced and then connected with each other. The P-wave and S-wave velocities began to decline, as shown in Figure 5a. Based on the ultrasonic wave velocities, the crack density of rock can be calculated. Previous research [10,11] presented the relationship between ultrasonic wave velocity and crack density, as shown as Equation (1):

$$
\xi=\frac{9\left[\left(1-\frac{{\overline{V_{s}}}^{2}}{V_{s}^{2}}\right)\left(3 \frac{{\overline{V_{p}}}^{2}}{\bar{V}_{s}^{2}}-4\right)\left(5 \frac{V_{p}^{2}}{V_{s}^{2}}-8\right)-4\left(\frac{V_{p}^{2}}{V_{s}^{2}}-\frac{{\overline{V_{p}}}^{2}}{{\overline{V_{s}}}^{2}}\right)\right]\left[3 \frac{\overline{V_{p}}}{{\overline{V_{s}}}^{2}}-2\right]}{32 \frac{{\overline{V_{p}}}^{2}}{{\overline{V_{s}}}^{2}}\left(3 \frac{\bar{V}_{p}^{2}}{{\overline{V_{s}}}^{2}}-4\right)\left(3 \frac{V_{p}^{2}}{V_{s}^{2}}-4\right)}
$$

where $\xi$ is the crack density in the rock sample, $V_{p}$ and $V_{s}$ are the P-wave and S-wave velocities in the damage-free rock sample, and $\overline{V_{p}}$ and $\overline{V_{s}}$ are the P-wave and S-wave velocities in the damage-bearing rock sample. Figure $5 b$ presents the crack density curves of rock salt under different confining pressures in the triaxial compression tests. The four curves have a consistent trend: first, decreasing remaining constant for a while, and then the increasing significantly. The lower the confining pressure, the greater the slope of the fracture density curve and the faster the crack development rate. The above results are effective verifications of crack growth inhibition by confining pressure. Additionally, the ultrasonic wave velocity and crack density can indeed illustrate the development of rock damage. However, we do not recommend regarding them as the damage prediction index for rock salt under triaxial compression tests, for the wave velocity change is not significant before the plastic deformation phase, and the interpretation of the waveform information, especially S-waves, was confounded by the subjective influence of the tester.

Ultrasonic waves will decay when there are granular structures, defects, and impurities in the medium. In addition, a part of the ultrasonic energy will convert into heat because of the friction between rock grains. All the above will lead to loss of ultrasonic energy, which is presented by the reduction of the ultrasonic wave amplitude. Figure $5 \mathrm{c}$ shows the changes of the P-wave and S-wave amplitude during the process of rock salt damage. $A$ was the amplitude when the rock was subjected 
to external stress and $A_{0}$ was the initial amplitude before the test. As can be seen from Figure $5 c$, the P-wave amplitude rose at first, then remained constant, and then decreased with the development of rock damage. What was interesting about the data in this figure was that the P-wave amplitude began to decrease after entering the plastic deformation stage. The attenuation did not happen at the brittle-ductile transition or the beginning of the plastic deformation stage. This meant that there were not enough new cracks in the sample to hinder the ultrasonic wave propagation at that moment, even though the sample had a large deformation.

The ultrasonic wave attenuation coefficient, $\alpha$, is used to indicate the degree of attenuation of sound waves as they propagate through the medium. It is defined using Equation (2):

$$
\alpha=\frac{20}{x} \lg \frac{A}{A_{0}}
$$

where $x$ is the propagation distance and $\lg$ is the logarithm. Figure $5 \mathrm{~d}$ provides the relationship between the ultrasonic wave attenuation coefficient and the axial stress-strain curves. The attenuation coefficient $\alpha$ had an increasing trend at the beginning of the test, remaining stable at the brittle-ductile transition stage. Subsequently, it slightly decreased when the sample entered the plastic deformation stage, and the slope began to increase as the test progressed. These results were consistent with the change in the ultrasonic amplitude.

(a)

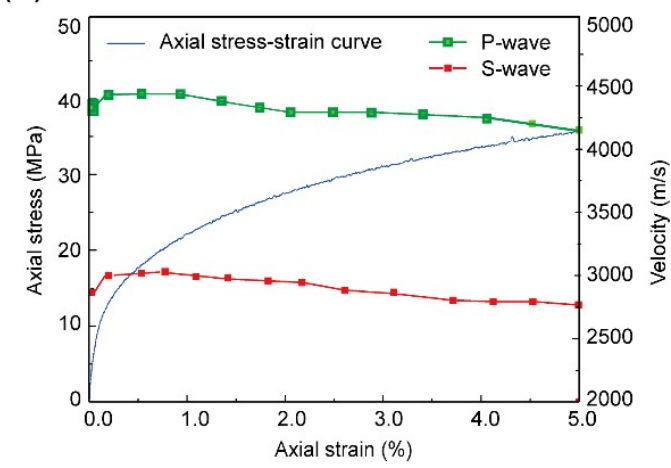

(c)

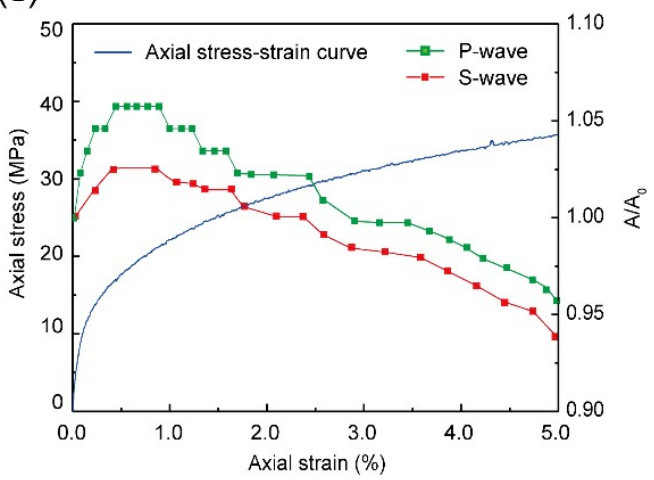

(b)

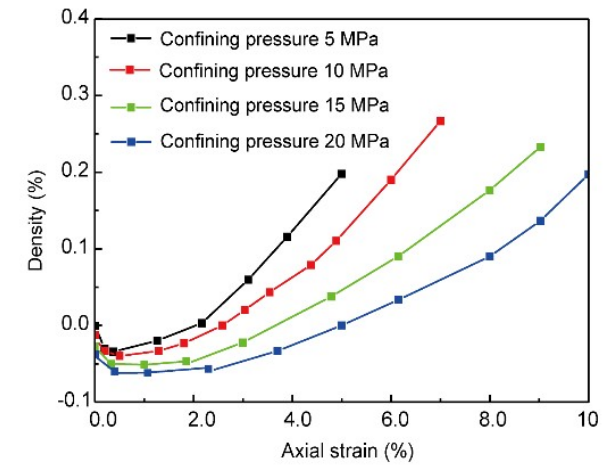

(d)

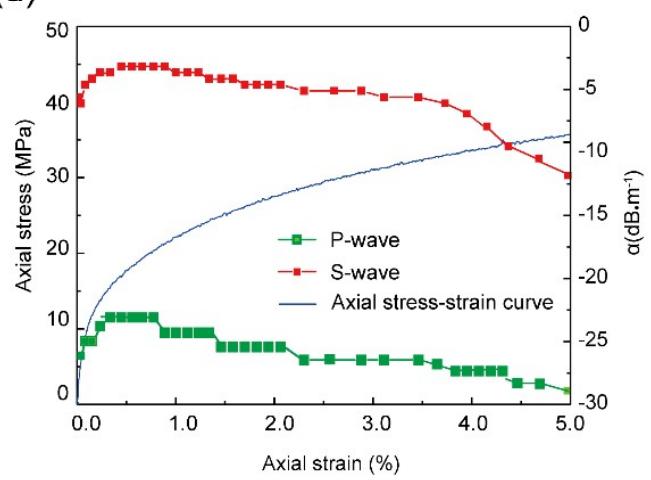

Figure 5. Ultrasonic wave characteristics of rock salt under a triaxial loading test: (a) the relationship of ultrasonic wave velocity and axial stress-stain curve; (b) the relationship of crack density and axial stress-stain curve; (c) the relationship of ultrasonic wave amplitude and axial stress-stain curve; and,

(d) the relationship of ultrasonic wave attenuation coefficient and axial stress-stain curve.

\subsection{AE Activity}

The AE activity is accompanied by the rock damage process with different release intensities. Six sensors work independently to monitor the AE activity of the rock sample. When the energy released 
is monitored by four or more sensors, the location of this source can be determined by the difference of arrival time. The calculation method is shown in Equation (3) [36].

$$
\left(x_{k}-x_{0}\right)^{2}+\left(y_{k}-y_{0}\right)^{2}+\left(z_{k}-z_{0}\right)^{2}=v_{p}{ }^{2}\left(t_{k}-t_{0}\right)^{2}
$$

where $x_{k}, y_{k}$, and $z_{k}$ are the sensor's (No. K) coordinates. $x_{0}, y_{0}$, and $z_{0}$ are the artificial testing coordinates. $v_{p}$ is the P-wave velocity. $t_{k}$ and $t_{0}$ are the excitation and reception time of the signal, respectively. Figure 6 presents the AE event number of rock salt under the confining pressure of 5, 10, 15 , and $20 \mathrm{MPa}$, respectively. The AE activity was weak and few AE events occurred at the beginning of the loading experiment. Subsequently, it started to be more active with increasing frequency. This was caused by salt crystal slippage in the sample and ensuing continuous energy release. Different from "hard" rocks, the main peak of AE activity of rock salt was difficult to find during the triaxial compression test for the energy was released by a series of continuous similar-strength earthquakes, and it was maintained at a high intensity until the end of the test.

(a)

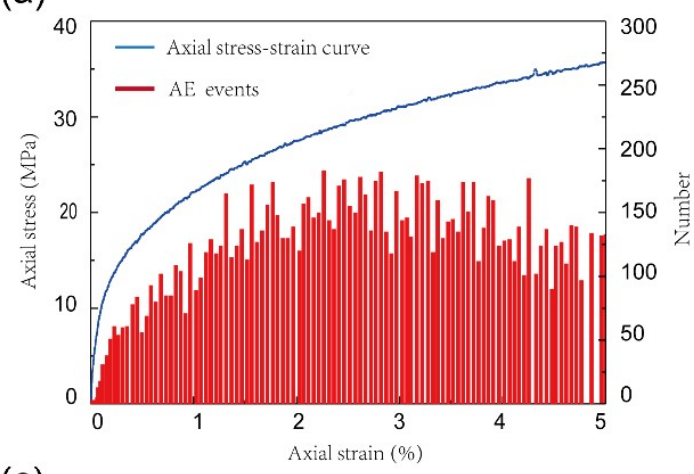

(c)

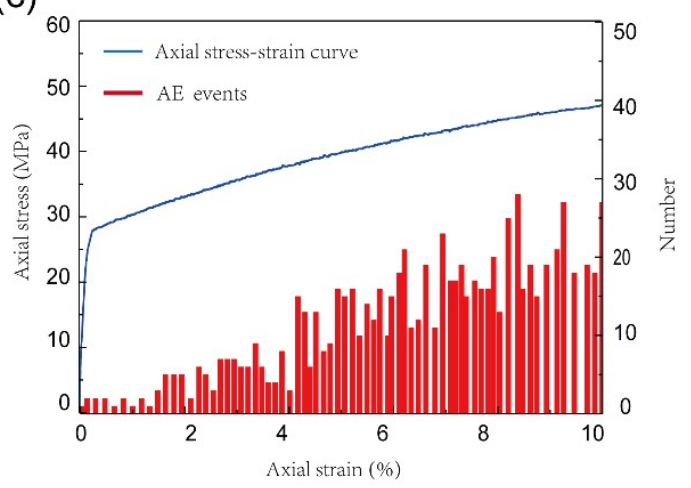

(b)

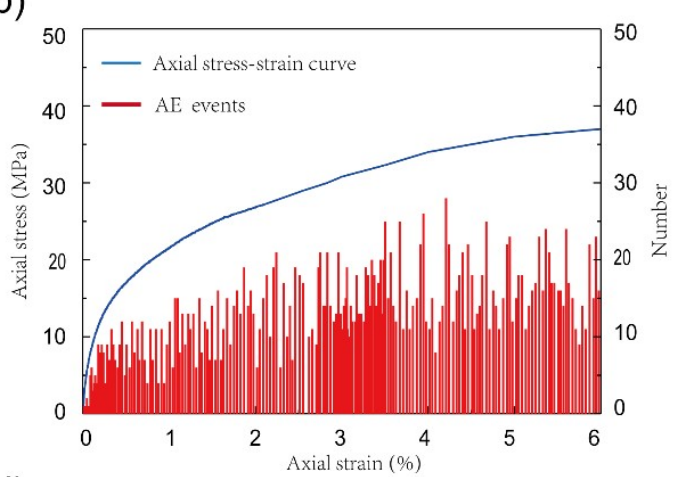

(d)

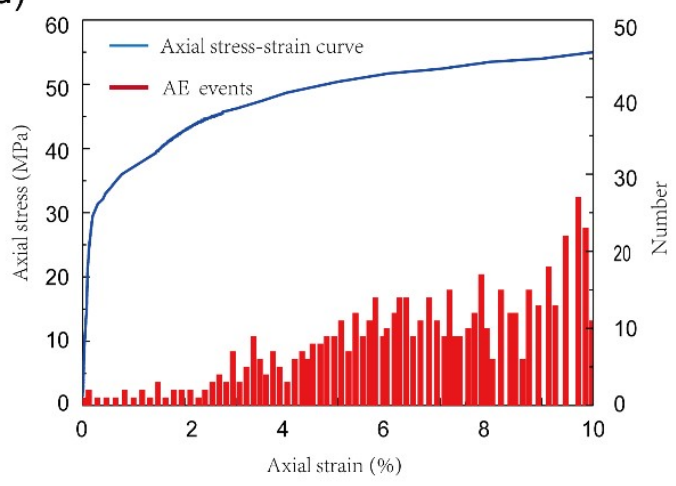

Figure 6. AE event number of rock salt under different confining pressure during the triaxial loading test: (a) confining pressure of $5 \mathrm{MPa}$; (b) confining pressure of $10 \mathrm{MPa}$; (c) confining pressure of $15 \mathrm{MPa}$; and, (d) confining pressure of $20 \mathrm{MPa}$.

The AE event map, which is a display of rock damage status, was calculated by the arrival time of AE signals received by six sensors, as shown in Figure 7. The AE events are more concentrated at the middle part of the salt samples, since the most severe damage occurred there. This map is a conclusive verification of rock damage. The sample became "thickened" after the loading test, and the maximum lateral deformation occurred in the middle area, resembling the shape of a drum. All of these features were consistent with the AE event map. In summary, the AE event map can clearly express the distribution and severity for rock damage, and it lays a foundation for quantitative evaluation of the damage degree of rock salt. 
(a)

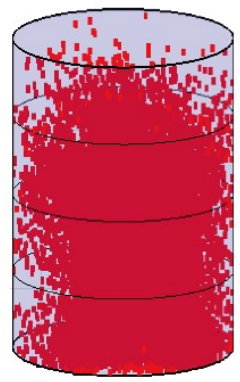

(b)

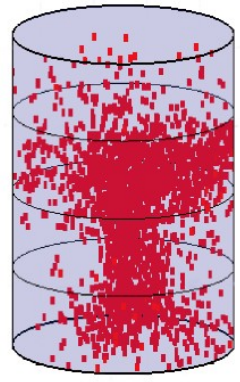

(c)

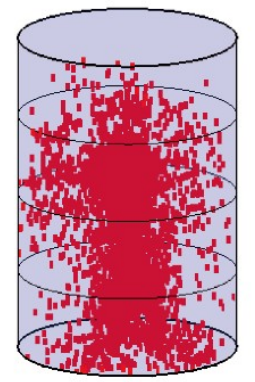

(d)

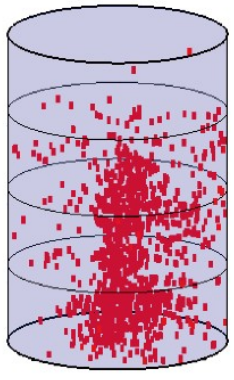

(e)

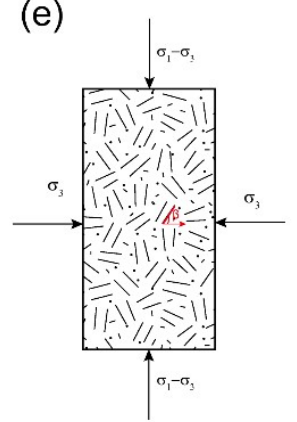

Figure 7. AE event maps of rock salt under different confining pressure during the triaxial loading test: (a) confining pressure of $5 \mathrm{MPa}$; (b) confining pressure of $10 \mathrm{MPa}$; (c) confining pressure of $15 \mathrm{MPa}$; (d) confining pressure of $20 \mathrm{MPa}$; and, (e) geometric relationship between micro-crack direction and stress direction.

As for the experimental evidence of $\mathrm{AE}$ events under the confining stress of 5, 10, 15, or $20 \mathrm{MPa}$, the AE activity clearly varied under different confining pressures, as shown in Figures 6 and 7 . According to the statistics results, $14763,7673,2674$, and $703 \mathrm{AE}$ events occurred from the test start to the axial strain of $8 \%$, under confining pressures $5,10,15$, and $20 \mathrm{MPa}$, respectively. The higher that the confining pressure was, the less the active the AE events were. Figure 7 presents the AE event maps of rock salt under different confining pressures, which clearly reflected that confining pressure had an inhibitory effect on AE activity. The relationship between confining pressure and AE activity has been studied previously [37], using the following expression:

$$
\tau_{\text {eff }}=\sigma_{s}-\left(c_{0}+\sigma_{N} \tan \varphi\right)
$$

where $\tau_{\text {eff }}$ is effective stress on fracture surface, $c_{0}$ is cohesion on fracture surface, $\varphi$ is the internal friction angle on the fracture surface, $\sigma_{S}$ is the shear stress on fracture surface that was caused by axial stress and confining pressure, and $\sigma_{N}$ is the vertical stress on fracture surface caused by axial stress and confining pressure. Using Equation (4) and the geometric relationship that is shown in Figure 7e, Equations (5) and (6) can be derived:

$$
\begin{gathered}
\sigma_{\mathrm{s}}=\left(\sigma_{1}-\sigma_{3}\right) \cos ^{2} \beta+\sigma_{3} \sin ^{2} \beta \\
\sigma_{N}=\left(\sigma_{1}-2 \sigma_{3}\right) \cos \beta \sin \beta
\end{gathered}
$$

where $\sigma_{1}$ is the axial stress, $\sigma_{3}$ is the confining pressure, and $\beta$ is the horizontal inclination of the fracture surface. When the axial loading stress was the same, the effective shear stress on the fracture surface became lower with increasing confining pressure, which inhibited crack expansion and AE activity.

\section{Discussions}

Rock deformation is accompanied by energy release, which can be recorded by AE sensors. The released energy is equal to the sum of the absolute value of the area between the envelope of the signal wave and the threshold line. Figure 8 presents the energy release process of rock salt under different confining pressures during the triaxial loading test. According to the energy fluctuation, the damage process of rock salt can be divided into four stages, as shown in Figure 8. The characteristics of each stage are described below.

(1) Stage I: At the beginning of the test, the AE activity of rock salt was weak, displaying very little energy release. At this stage, the rock sample was under a confining pressure and axial loading stress on the top, which can be regarded as external energy input. The sample was experiencing elastic and compression deformation, and the energy absorption from the surrounding system was at its highest level. 
(2) Stage II: With increasing axial loading stress, the energy input from the external system continued to increase. However, energy in the sample reached its limit, and the rock salt had no further ability to absorb energy. Therefore, the excess energy had to be released in another way: it was consumed in the sliding and embedding actions among the salt crystals, followed by the generation and expansion of micro-cracks. This stage corresponds to the brittle-ductile transition of the rock salt in which irreversible rock damage occurred. The AE activity continued to increase throughout this stage.

(3) Stage III: At this stage, the steady rise in AE energy release changed to an irregular fluctuating trend and the energy release rate remained at a high level. Due to the rapid expansion of internal cracks in the rock, the rock salt produced large deformation. The AE activity was extremely intense, and the released energy reached its peak at the end of this stage. Some researchers thought $[38,39]$ that there was a period of stagnation of AE before it reaches the energy peak. After the peak point, the energy release intensity dropped significantly. Due to the large deformation characteristics and strain hardening properties of rock salt, the triaxial compression strength cannot be accurately determined. In this study, the stress when the AE energy is at its peak is defined as the "damage ultimate stress", which has the same unit and physical meaning as the triaxial compressive strength. The triaxial compression strength was replaced with the "damage ultimate stress", from which the friction angle and cohesion of rock salt can be determined.

(4) Stage IV: When the axial stress exceeded the damage stress limit, significant structural damage occurred with a large number of connected cracks in the sample. However, the rock salt still had a stress carrying ability. The intensity of AE activity decreased significantly, but it was still active.

(a)

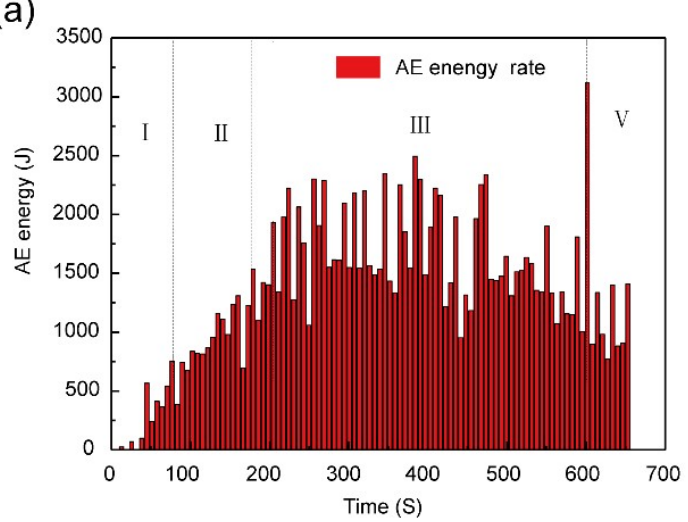

(c)

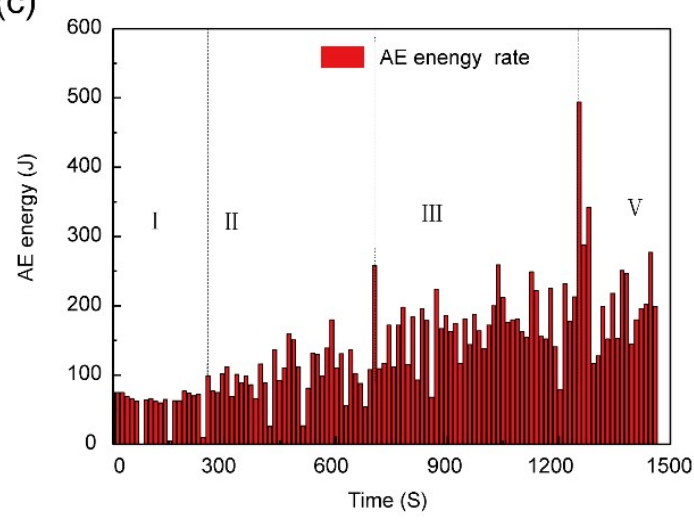

(b)

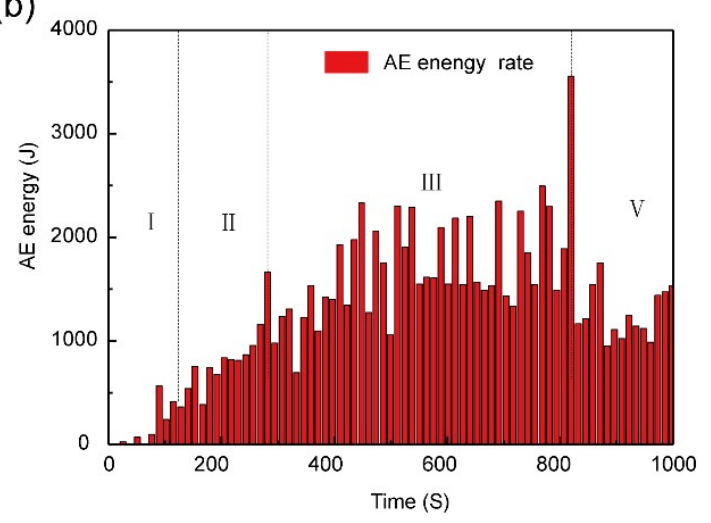

(d)

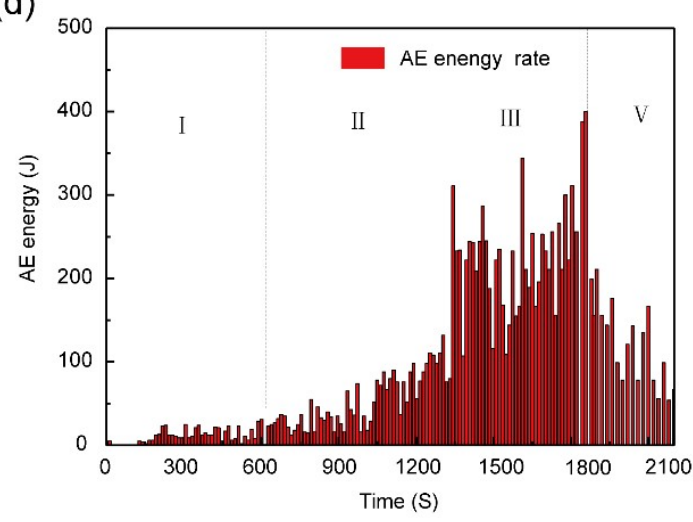

Figure 8. Histogram of AE energy of rock salt under triaxial compression test: (a) confining pressure of $5 \mathrm{MPa}$; (b) confining pressure of $10 \mathrm{MPa}$; (c) confining pressure of $15 \mathrm{MPa}$; and, (d) confining pressure of $20 \mathrm{MPa}$.

In the above study, four critical stresses were involved: crack initiation threshold stress, dilatancy boundary stress, short-term strength, and damage ultimate stress. These critical stresses of rock salt 
under different confining pressures during the triaxial loading test were presented, as shown in Table 1 . The crack initiation threshold is the end of the linear elastic deformation stage, after which the salt samples enter a process with elastic and plastic deformation coexisting when the axial stress exceeds the crack initiation threshold. It is the dividing line between recoverable and unrecoverable deformation, with important engineering value. Rock dilatancy is caused by the generation of internal micro cracks or the movement of crystals. The dilatancy boundary stress is obtained by the peak of the axial stress-strain curve, and this stress is $60-80 \%$ of the rock strength. In this study, the dilatancy of rock salt occurred in the brittle-ductile transition stage, and it was inferred that this dilatancy phenomenon resulted in the motion of salt crystal slip and not the generation of cracks, for the ultrasonic wave velocity did not drop, but it remained stable. When the confining stresses of the rock were 5, 10, 15, and $20 \mathrm{MPa}$, the crack initiation thresholds were $59.76 \%, 67.40 \%, 67.51 \%$, and $63.06 \%$ of the short-term strength of the rock salt, respectively; and, the dilatancy boundary stresses were $80.47 \%, 80.11 \%$, $77.66 \%$, and $72.97 \%$ of the short-term strength of the rock salt, respectively. According to these data, it is inferred that the stress interval between the crack initiation threshold and the dilatancy boundary is short, and that the dilatancy will happen soon after the linear elastic deformation stage. Subsequently, the volume strain curve will decrease after dilatancy, and the stress when the volumetric strain is " 0 " is defined as the short-term strength of rock salt. The short-term strength is a particularly important boundary of the brittle-ductile transition stage and the plastic deformation stage. When the axial stress exceeds the short-term strength, the damage of rock salt will dramatically develop, as seen in the decline of ultrasonic wave velocity and the rising of AE events. The rock salt enters a stage of accelerated plastic deformation, with uncontrollable crack development. The internal structure of the rock has undergone considerable changes, which is extremely detrimental to the sealing and stability of underground gas storage. When the confining stress changed from 5 to $20 \mathrm{MPa}$, the short-term strength of rock salt increased from 16.9 to $22.2 \mathrm{MPa}$. It is clear that the confining stress has a certain influence on the short-term strength of rock salt, yet the effect is not extraordinarily strong. In this study, the damage ultimate stress was determined by the peak of the AE energy release of the rock salt. It is seen as the ultimate strength of the rock, like the triaxial compressive strength of hard rock. When the load on the rock exceeds this value, the rock will break and the underground structure will not be stable.

Table 1. Four critical strengths of rock salt under triaxial compression test.

\begin{tabular}{ccccc}
\hline \multirow{2}{*}{ Critical Strength/MPa } & \multicolumn{4}{c}{ Confining Pressure } \\
\cline { 2 - 4 } & $\mathbf{5} \mathbf{~ M P a}$ & $\mathbf{1 0} \mathbf{~} \mathbf{P a}$ & $\mathbf{1 5} \mathbf{~} \mathbf{P a}$ & $\mathbf{2 0} \mathbf{~} \mathbf{P a}$ \\
\hline Crack initiation threshold stress & 10.1 & 12.2 & 13.3 & 14.0 \\
Dilatancy boundary stress & 13.6 & 14.5 & 15.3 & 16.2 \\
Short-term strength & 16.9 & 18.1 & 19.7 & 22.2 \\
Damage ultimate stress & 27.1 & 29.9 & 41.2 & 52.3 \\
\hline
\end{tabular}

\section{Conclusions}

In this study, controlled laboratory experiments on salt rock samples under triaxial stress were performed to analyze the ultrasonic wave characteritics and AE activities during the rock damage process. The conclusions of the study are summarized, as follows:

1. The deformation of rock salt under triaxial loading stress was divided into four stages with individual characteristics. The elastic compression stage was a short-term and reversible process, with a slight increase of ultrasonic wave velocity and few $\mathrm{AE}$ events. This stage ended at the crack initiation threshold, after which the brittle-ductile transition stage with crack initiation began with a controllable crack development. At this stage, the deformation was mainly due to the slippage of salt grains. AE activity began to increase, while the S-waves' and P-waves' velocities remained constant. When the loading stress exceeded the dilatancy boundary, the rock salt entered the brittle-ductile transition of damage initiation stage, with intense AE activity and fluctuation of ultrasonic wave velocities. The last 
stage was plastic deformation with strain hardening, and the sample exhibited a typical drum-shaped failure, however, it did not "yield" at the end of the test. The AE activity was especially pronounced, and the P-waves' and S-waves' velocities began to significantly decrease.

2. Ultrasonic wave velocity, crack density, ultrasonic wave amplitude, and attenuation coefficient have consistent changes with the damage process of the rock salt under the triaxial compression tests. However, the ultrasonic wave amplitude is recommended as the damage prediction index, not the ultrasonic wave velocity or crack density. The wave velocity attenuation is not significant before the plastic deformation phase, and the interpretation of the waveform information, especially S-waves, was confounded by the subjective influence of the tester. Additionally, the higher the confining pressure level, the smaller the ultrasonic wave fluctuation.

3. The confining pressure inhibited the crack expansion and AE activity. The higher the confining pressure, the lower the effective shear stress on the fracture surface and the less pronounced the AE events. Based on the AE activity and energy release characteristics, the damage ultimate stress was defined and then determined. It could be regarded as the triaxial compression strength and it could play a key role in the evaluation of the stability of underground engineering structures.

4. The ultrasonic wave test is an active testing method, and AE activity monitoring is a passive testing method. Both technologies can reveal the rock damage process in different ways. A mathematical model relating the two types of parameters should be obtained to precisely and accurately predict the rock damage evolution. This goal is the next research direction of the authors.

Author Contributions: Data curation, H.L., Z.D., W.Y. and H.Y.; Formal analysis, H.L.; Investigation, H.L. and Z.D.; Methodology, Z.O.; Resources, H.Y.; Writing—original draft, W.Y.; Writing—review \& editing, B.L.

Acknowledgments: The authors acknowledge the financial support of the National Natural Science Foundation for Young Scientists of China (Grant No. 41602328), the Natural Science Foundation of Hebei Province (Grant No. D2017210182 and No. E2018210046), and the collaborative innovation center of disaster prevention and mitigation for large infrastructure of Hebei province. The authors also wish to thank the reviewers for constructive comments and suggestions that have helped to improve our manuscript.

Conflicts of Interest: The authors declare no conflict of interest.

\section{References}

1. Bérest, P.; Bergues, J.; Brouard, B.; Durup, J.G.; Guerber, B. A salt cavern abandonment test. Int. J. Rock. Mech. Min. 2001, 38, 357-368. [CrossRef]

2. Ma, H.L.; Yang, C.H.; Li, Y.P.; Shi, X.L.; Liu, J.F.; Wang, T.T. Stability evaluation of the underground gas storage in rock salts based on new partitions of the surrounding rock. Environ. Earth Sci. 2015, 73, 6911-6925. [CrossRef]

3. Schulze, O.; Popp, T.; Kern, H. Development of damage and permeability in deforming rock salt. Eng. Geol. 2001, 61, 163-180. [CrossRef]

4. Yang, C.H.; Daemen, J.J.K.; Yin, J.H. Experimental investigation of creep behavior of salt rock. Int. J. Rock Mech. Min. 1999, 36, 233-242. [CrossRef]

5. Bérest, P.; Brouard, B. Safety of salt caverns used for underground storage-Blow out; Mechanical instability; Seepage; Cavern abandonment. Oil. Gas. Sci. Technol. 2003, 58, 361-384. [CrossRef]

6. Neal, J.T.; Magorian, T.R. Geologic site characterization (GSC) principles derived from storage and mining projects in salt, with application to environmental surety. Environ. Geol. 1997, 29, 165-175. [CrossRef]

7. Sovacool, B.K. The costs of failure: A preliminary assessment of major energy accidents, 1907-2007. Energy Policy 2008, 36, 1802-1820. [CrossRef]

8. Yang, C.H.; Jing, W.J.; Daemen, J.J.K.; Zhang, G.M.; Du, C. Analysis of major risks associated with hydrocarbon storage caverns in bedded salt rock. Reliab. Eng. Syst. Saf. 2013, 113, 94-111. [CrossRef]

9. Lu, X.B.; Wu, J.Y. Theory and Application of Impact Elastic Wave; China Water and Power Press: Beijing, China, 2016; pp. 6-7, ISBN 978-7-5170-4481-9.

10. Oconnell, R.J.; Budiansky, B. Seismic veloctities in dry and saturated cracked solid. J. Geophys. Res. 1974, 79, 5412-5425. [CrossRef]

11. Budiansky, B.; Oconnell, R.J. Elastic moduli of a cracked solid. Int. J. Solids Struct. 1976, 12, 81-97. [CrossRef] 
12. Bellanger, M.; Remy, J.M.; Homand, F. Ultrasonic wave attenuation as a tool for estimating frost action on limestone rocks. Mater. Struct. 1996, 29, 552-561. [CrossRef]

13. Falls, S.D.; Young, R.P. Acoustic emission and ultrasonic-velocity methods used to characterise the excavation disturbance associated with deep tunnels in hard rock. Tectonophysics 1998, 289, 1-15. [CrossRef]

14. Ai, H.R.A.; Ahrens, T.J. Effects of shock-induced cracks on the ultrasonic velocity and attenuation in granite. J. Geophys. Res. 2007, 112, b01201. [CrossRef]

15. Chaki, S.; Takarli, M.; Agbodjan, W.P. Influence of thermal damage on physical properties of a granite rock: Porosity, permeability and ultrasonic wave evolutions. Constr. Build. Mater. 2008, 22, 1456-1461. [CrossRef]

16. Vasconcelos, G.; Lourenco, P.B.; Alves, C.A.S.; Pamplona, J. Ultrasonic evaluation of the physical and mechanical properties of granites. Ultrason 2008, 48, 453-466. [CrossRef] [PubMed]

17. Wang, Y.; Li, C.H. Investigation of the P- and S-wave velocity anisotropy of a Longmaxi formation shale by real-time ultrasonic and mechanical experiments under uniaxial deformation. J. Petrol. Sci. Eng. 2017, 158, 253-267. [CrossRef]

18. Li, H.R.; Dong, Z.K.; Yang, Y.; Liu, B.; Chen, M.Y.; Jing, W.J. Experimental study of damage development in salt rock under uniaxial stress using ultrasonic velocity and acoustic emissions. Appl. Sci. 2018, 8. [CrossRef]

19. Chen, J.; Kang, Y.F.; Liu, W.; Fan, J.Y.; Jiang, D.Y.; Chemenda, A. Self-healing capacity of damaged rock salt with different initial damage. Geomech. Eng. 2018, 15, 615-620. [CrossRef]

20. Chen, J.; Ren, S.; Yang, C.H.; Jiang, D.Y.; Li, L. Self-healing characteristics of damaged rock salt under different healing conditions. Materials 2013, 6, 3438-3450. [CrossRef]

21. Mogi, K. Study of elastic shocks caused by the fracture of heterogeneous materials and its relation to earthquake phenomena. Bull. Earthq. Res. Inst. 1962, 40, 125-173.

22. Rao, M.; Ramana, Y.V. A study of progressive failure of rock under cyclic loading by ultrasonic and ae monitoring techniques. Rock Mech. Rock Eng. 1992, 25, 237-251. [CrossRef]

23. Filimonov, Y.L.; Lavrov, A.V.; Shafarenko, Y.M.; Shkuratnik, V.L. Memory effects in rock salt under triaxial stress state and their use for stress measurement in a rock mass. Rock Mech. Rock Eng. 2001, 34, $275-291$. [CrossRef]

24. Rodríguez, P.; Arab, P.B.; Celestino, T.B. Characterization of rock cracking patterns in diametral compression tests by acoustic emission and petrographic analysis. Int. J. Rock Mech. Min. 2016, 83, 73-85. [CrossRef]

25. Chen, G.Q.; Guo, F.; Wang, J.C.; Zhou, Y.X. Experimental study of creep properties of quartz sandstone after freezing-thawing cycles. Rock Soil Mech. 2017, 38, 203-210. [CrossRef]

26. Ge, Z.L.; Sun, Q. Acoustic emission (AE) characteristics of granite after heating and cooling cycles. Eng. Fract. Mech. 2018, 200, 418-429. [CrossRef]

27. Ren, S.; Bai, Y.M.; Jiang, D.Y.; Yang, C.H.; Chen, J. Experimental research on acoustic emission property of salt rock under cyclic loading. Rock Soil Mech. 2012, 33, 1613-1618. [CrossRef]

28. Ren, S.; Bai, Y.M.; Zhang, J.P.; Jiang, D.Y.; Yang, C.H. Experimental investigation of the fatigue properties of salt rock. Int. J. Rock Mech. Min. 2013, 64, 68-72. [CrossRef]

29. Alkan, H.; Cinar, Y.; Pusch, G. Rock salt dilatancy boundary from combined acoustic emission and triaxial compression tests. Int. J. Rock. Mech. Min. 2007, 44, 108-119. [CrossRef]

30. Yang, Y.J.; Wang, D.C.; Guo, M.F.; Li, B. Study of rock damage characteristics based on acoustic emission tests under triaxial compression. Chin. J. Rock Mech. Eng. 2014, 33, 98-104. [CrossRef]

31. Li, Y.; Zhang, K.; Wu, X.W. Study of ultrasonic wave characteristics of shale in triaxial compression tests. J. Geophys. Eng. 2018, 15, 2183-2193. [CrossRef]

32. Jia, S.P.; Luo, J.Z.; Yang, J.P.; Gao, M.; Gong, J. An elastoplastic damage constitutive model for salt rock considering confining pressure effect. Rock Soil Mech. 2015, 36, 1549-1556. [CrossRef]

33. Wang, B.; Zhu, J.B.; Yan, P.; Huang, S.L.; Wu, A.Q. Damage Strength Determination of Marble and its Parameters Evaluation based on Damage Control Test. Chin. J. Rock Mech. Eng. 2012, 31, 3967-3973.

34. Liu, J.F.; Bian, Y.; Zheng, D.W.; Wu, Z.D.; Li, T.Y. Discussion on strength analysis of salt rock under triaxial compressive stress. Rock Soil Mech. 2014, 35, 919-925. [CrossRef]

35. Guo, Y.T.; Yang, C.H.; Fu, J.J. Experimental research on mechanical characteristics of salt rock under triaxial unloading test. Rock Soil Mech. 2012, 33, 725-732. [CrossRef]

36. Geiger, L. Probability method for the determination of earthquake epicenters from the arrival time only. Bull. St. Louis Univ. 1912, 8, 56-71. 
37. Ai, T.; Zhang, R.; Liu, J.F.; Zhao, X.P.; Ren, L. Space-time evolution rules of acoustic emission locations under triaxial compression. J. China Coal Soc. 2011, 36, 2048-2057. [CrossRef]

38. Fang, Y.R.; Geng, N.G.; Zhang, Z.; Wu, K.T. Relative quiet of acoustic emissions anterior rock rupture. Earthq. Res. Sichuan 1988, 3, 5-8.

39. Yin, X.G.; Li, S.L.; Tang, H.Y.; Pei, J.L. Study on quiet period and its fractal characteristics of rock failure acoustic emission. Chin. J. Rock Mech. Eng. 2009, 28 (Suppl. 2), 3383-3390.

(C) 2019 by the authors. Licensee MDPI, Basel, Switzerland. This article is an open access article distributed under the terms and conditions of the Creative Commons Attribution (CC BY) license (http:/ / creativecommons.org/licenses/by/4.0/). 